\title{
Erratum to: Quantification of the cellular dose and characterization of nanoparticle transport during in vitro testing
}

Grigore Rischitor ${ }^{1}$, Mariantonietta Parracino², Rita La Spina', Patricia Urbán¹, Isaac Ojea-Jiménez , Elena Bellido ${ }^{1}$, Andrea Valsesia', Sabrina Gioria', Robin Capomaccio ${ }^{1}$, Agnieszka Kinsner-Ovaskainen ${ }^{1}$, Douglas Gilliland', François Rossi ${ }^{1}$ and Pascal Colpo ${ }^{1 *}$

\section{Erratum}

After the publication of this work [1] it was noticed that the author name 'Patricia Urbán' was incorrectly spelt as 'Patrizia Urbán'. This has now been corrected in the author list.

\section{Author details}

'European Commission Joint Research Centre, Institute for Health and Consumer and Protection, Nanobiosciences Unit, Via E. Fermi 2749, 21027 Ispra, VA, Italy. ${ }^{2}$ Present Address: Nanoimmunotech S.L., Av. de la Autonomía, 50003 Zaragoza, Spain.

Received: 6 December 2016 Accepted: 6 December 2016

Published online: 09 December 2016

\section{Reference}

1. Rischitor G, Parracino M, La Spina R, Urbán P, Ojea-Jiménez I, Bellido E, et al.

Quantification of the cellular dose and characterization of nanoparticle

transport during in vitro testing. Part Fibre Toxicol. 2016;13:47.

\footnotetext{
* Correspondence: pascal.colpo@ec.europa.eu

${ }^{1}$ European Commission Joint Research Centre, Institute for Health and Consumer and Protection, Nanobiosciences Unit, Via E. Fermi 2749, 21027 Ispra, VA, Italy
} 